\title{
Intracuneate mechanisms underlying primary afferent cutaneous processing in anaesthetized cats
}

\author{
Cristina Soto, Juan Aguilar, Francisco Martín-Cora, Casto Rivadulla, Antonio Canedo
}

\begin{abstract}
The cutaneous primary afferents from the upper trunk and forelimbs reach the medial cuneate nucleus in their way towards the cerebral cortex. The aim of this work was twofold: (i) to study the mechanisms used by the primary afferents to relay cutaneous information to cuneate cuneolemniscal (CL) and noncuneolemniscal (nCL) cells, and (ii) to determine the intracuneate mechanisms leading to the elaboration of the output signal by CL cells. Extracellular recordings combined with microiontophoresis demonstrated that the primary afferent cutaneous information is communicated to CL and nCL cells through AMPA, NMDA and kainate receptors. These receptors were sequentially activated: AMPA receptors participated mainly during the initial phase of the response, whereas kainate- and NMDA-mediated activity predominated during a later phase. The involvement of NMDA receptors was confirmed by in vivo intracellular recordings. The cutaneous-evoked activation of CL cells was decreased by GABA and increased by glycine acting at a strychnine-sensitive site, indicating that glycine indirectly affects CL cells. Two subgroups of nCL cells were distinguished based on their sensitivity to iontophoretic ejection of glycine and strychnine. Overall, the results support a model whereby the primary afferent cutaneous input induces a centre-surround antagonism in the cuneate nucleus by activating (via AMPA, NMDA and kainate receptors) and disinhibiting (via serial glycinergicGABAergic interactions) a population of CL cells with overlapped receptive fields that at the same time inhibit (via GABAergic cells) other neighbouring CL cells with different receptive fields.
\end{abstract}

\section{Introduction}

All tetrapods contain a dorsal column nucleus in the hindbrain, which is subdivided according to the termination of primary afferents from the upper trunk and forelimbs (cuneate nucleus, $\mathrm{CN}$ ) and from the lower trunk and hindlimbs (gracile nucleus). In addition, these dorsal column nuclei (DCN) are segregated into sectors based mainly on anatomical features that are phylogenetically ancient: (i) the termination of primary afferents carrying different somesthetic submodalities topographically organized, (ii) neuronal circuitry, (iii) intrinsic organization and (iv) target location (Dykes et al., 1982; Berkley et al., 1986; Rustioni \& Weinberg, 1989)

The DCN dorsal middle region comprises two major types of neurons: glutamatergic cells projecting to the medial lemniscus (cuneolemniscal, CL, cells), and local-circuit inhibitory cells (non cuneolemniscal, nCL, cells) (Barbaresi et al., 1986; Berkley et al., 1986; Rustioni \& Weinberg, 1989). Both classes of neurons receive cutaneous input and can be distinguished by electrically stimulating the contralateral medial lemniscus (ML) (Amassian \& de Vito, 1957; Gordon \& Seed, 1961; Andersen et al., 1964; Schwartzkroin et al., 1974; Canedo et al., 1998). The CL cells are arranged in cellular nests (Ramón y Cajal, 1909) or clusters (Kuypers \& Tuerk, 1964), receiving monosynaptic contact exclusively from fibers of a single nerve (Andersen et al., 1964). The nCL cells are intermingled with, and form a shell surrounding, the clustered CL cells, and may receive monosynaptic influence from different nerves (Andersen et al., 1964).

The activity of DCN neurons is governed by the balance between excitatory and inhibitory inputs: glutamate, gamma aminobutyric acid (GABA) and glycine are the neurotransmitters sculpting the cutaneous receptive fields (Aguilar et al., 2003). The primary afferents release glutamate (Banna \& Jabbur, 1989; Broman, 1994; De Biasi et al., 1994; Deuchars et al., 2000; Núñez \& Buño, 2001), which might differently affect CL and nCL cells because the former express predominantly the GluR3 subunit of the amino-3-hydroxy-5-methyl-isoxazol-propionate (AMPA) receptor whereas the nCL neurons express the GluR1 subunit or the GluR2 subunit (Popratiloff et al., 1997). The recent introduction of AMPA receptor antagonists (GYKI compounds) allows us to address whether kainate receptors (Paternain et al., 1995) are also implicated in the fast DCN response induced by primary afferents. Furthermore, the 
glutamate released from primary afferents may also influence DCN activity through $N$-methyl-d-aspartate (NMDA) receptors (Deuchars et al., 2000; but see Núñez \& Buño, 2001).

Recently, we have shown that cortical stimulation increases the centre-surround antagonism at the CN by: (i) monosynaptically activating CL cells topographically aligned through non-NMDA and NMDA receptors, (ii) producing lateral GABAergic inhibition on topographically unaligned CL cells and (iii) disinhibiting CL cells topographically aligned through serial glycinergic-GABAergic interactions (Aguilar et al., 2003). Paradoxically, this kind of information is unknown for the principal input to the nucleus, the primary afferents. It remains unknown whether the intracuneate circuitry described for cortical input is shared by primary afferents carrying cutaneous information. Accordingly, the present study was undertaken to explore the postsynaptic mechanisms used by the cutaneous primary afferent fibers to influence $\mathrm{CL}$ and $\mathrm{nCL}$ cells upon stimulation of their excitatory receptive fields.

\section{Materials and methods}

All animal experiments described here conformed to the Spanish Physiological Society, the International Council for Laboratory Animal Science and the European Union (statute no. 86/809). Data were obtained from 24 anaesthetized and paralysed cats of both sexes weighing 3-4.6 kg. Surgical and electrophysiological methods were as previously described in detail (Aguilar et al., 2003). Surgical anesthesia was induced with ketamine $\mathrm{HCl}(10-20 \mathrm{mg} / \mathrm{kg}$ i.m.) and continued with $\alpha$-chloralose $(60 \mathrm{mg} / \mathrm{kg}$ i.v., $n=12)$ or sodium pentobarbital $(35 \mathrm{mg} / \mathrm{kg}$ i.v., $n=12)$. There was no evidence that choice of anesthetic affected the results obtained. A bilateral pneumothorax was routinely performed, the expired $\mathrm{CO}_{2}$ was maintained at $4 \pm 0.5 \%$, a pH-balanced solution of $5 \%$ glucose in physiological saline was continuously infused $\left(4 \mathrm{~mL} / \mathrm{h}\right.$ i.v.), and the temperature was maintained near $37.5^{\circ} \mathrm{C}$ by a thermostatically controlled electric blanket and an overhead radiant heat lamp.

The dorsal medulla was exposed to insert recording electrodes in the middle $\mathrm{CN}$, running from the obex to about $4 \mathrm{~mm}$ caudal to it (Fyffe et al., 1986); a bipolar stimulating electrode stereotaxically placed in the contralateral ML served to identify antidromically CL cells according to standard criteria, including in all cases the collision test [see Figs 1, A2 (inset), 4, B2, and 5B). Finally, a concentric bipolar electrode was lowered 1-1.5 mm deep in the lateral tip of the cruciate sulcus to provide a continuous record of electrocorticographic activity. 


\section{A. $\mathrm{CL}$ cells. Receptive Field Stimulation (1Hz, 1ms bin)}
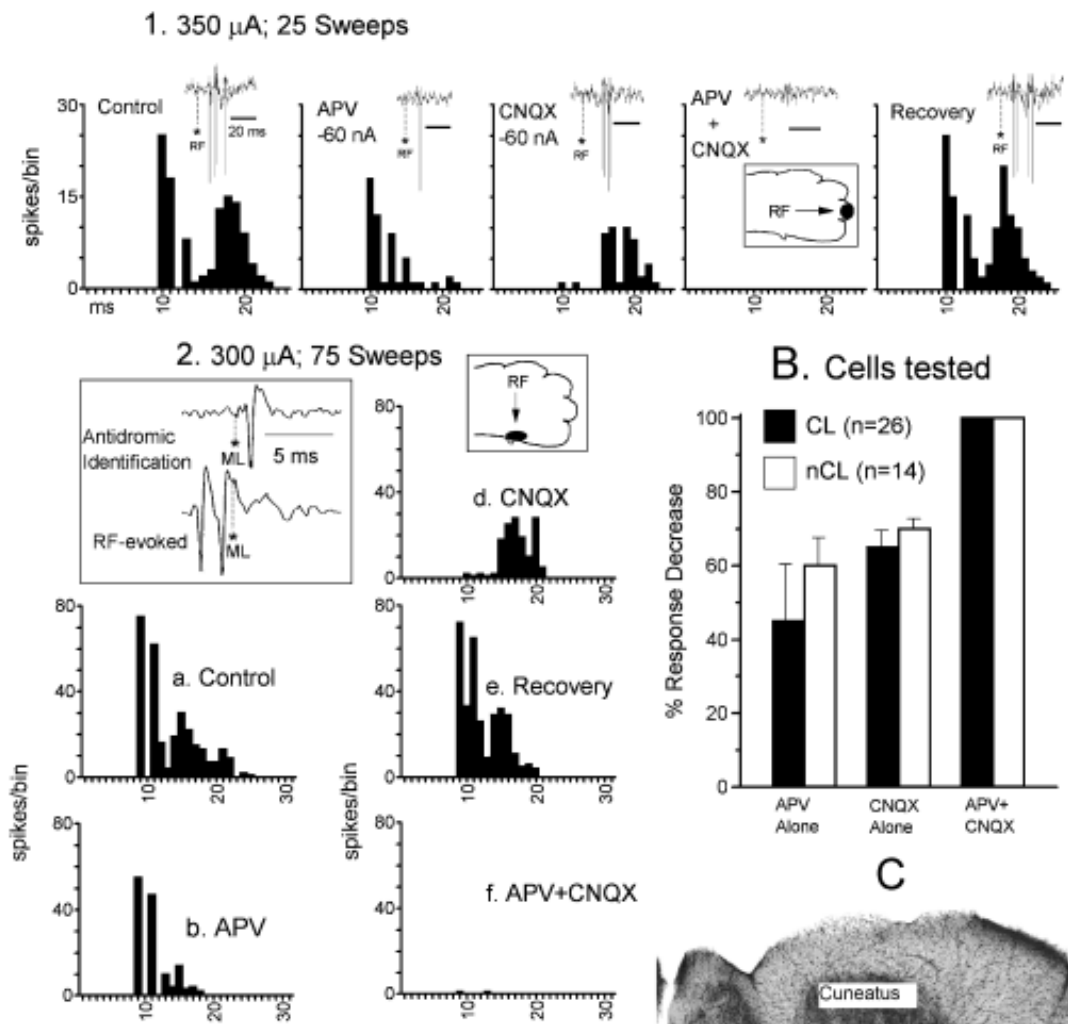

B. Cells tested
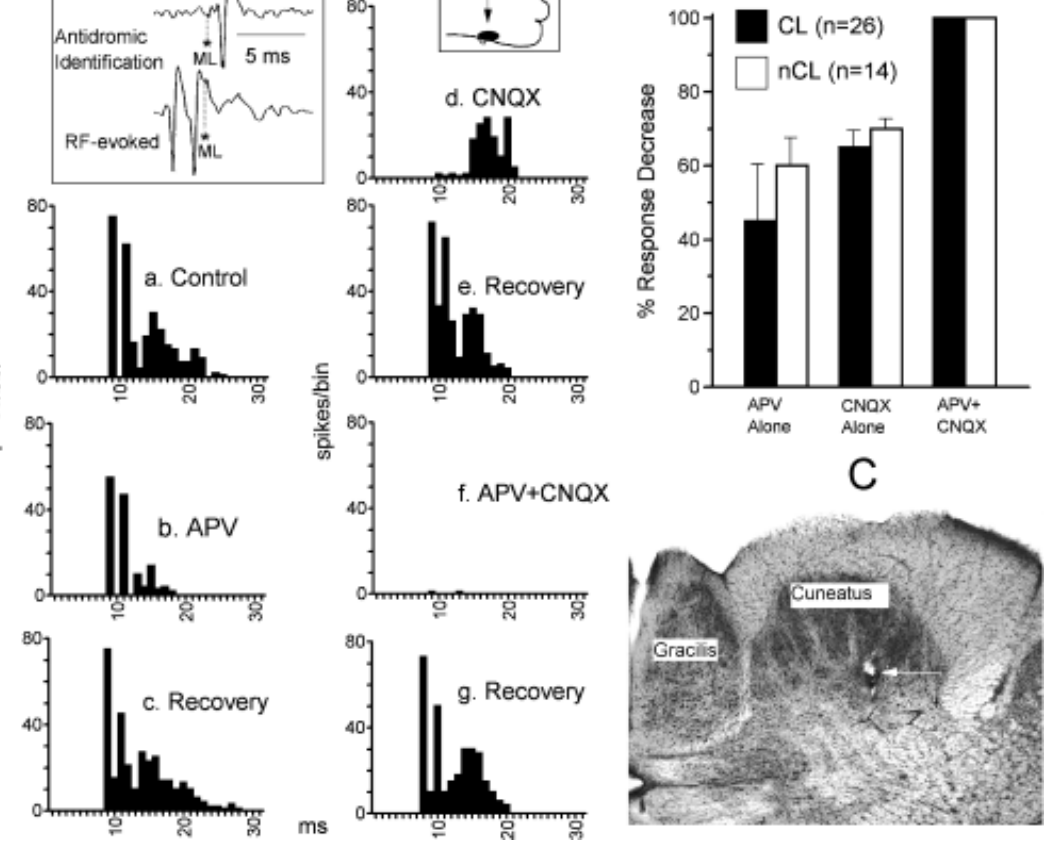

Figure 1. The receptive field (RF)-evoked excitation is mediated through non-NMDA and NMDA receptors. (A1) The cutaneousinduced activation of a CL neuron was decreased by ejection of APV alone or CNQX alone and subsequently abolished by the simultaneous ejection of both drugs; single specimen records are shown for each case at the insets with the RF stimuli marked by asterisks. (A2) Antidromic identification of a different CL cell, inset, with the medial lemniscus (ML) stimuli signaled by asterisks. Different successive treatments (from a to g) show the decrease of the cutaneous-evoked response after single APV (b) and CNQX (d) ejection, and suppression of the primary response after concurrent ejection of both drugs (f). In this and subsequent figures the inset diagrams show the approximate location and size of the cutaneous RF for each of the cells. (B) The average decrease (mean \pm SEM) of the cutaneous-evoked activation of the sampled cells with each treatment. (C) Photomicrograph of a coronal histological section showing an electrolitic lesion within the cuneate nucleus (marked by an arrow). 

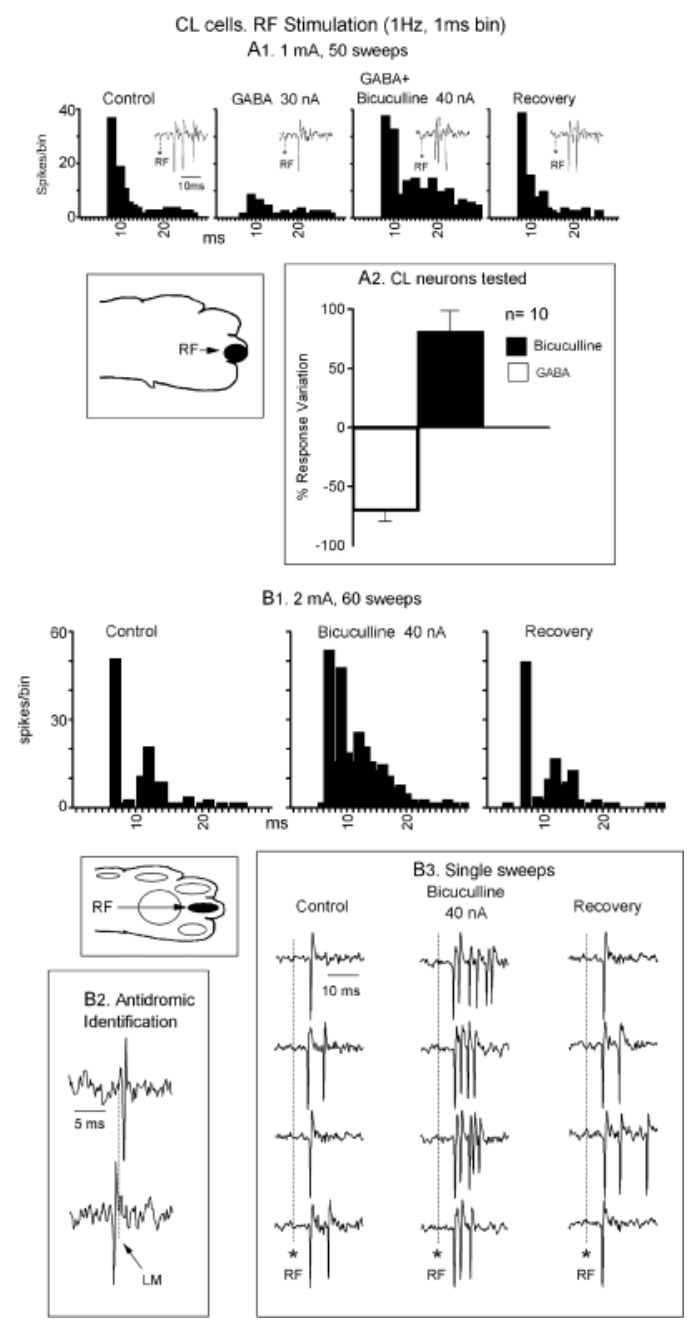

Figure 4. Effect of bicuculline on CL cells. Two different CL neurons (A1 and B) showing that bicuculline not only reversed the effect of GABA (A1) but also increased the cutaneous-evoked response relative to control (quantification shown in the diagram for the tested CL cells) and unmasked the doublets suppressed by high-intensity stimulation (columns comprising four single sweeps in B3, with the stimulus artifacts indicated by asterisks). (B2) Antidromic identification of the cell shown in B1 and B3, with the ML stimulus indicated by asterisks. Single responses to RF stimulation (stimuli indicated by asterisks) are shown in the insets to A1. 

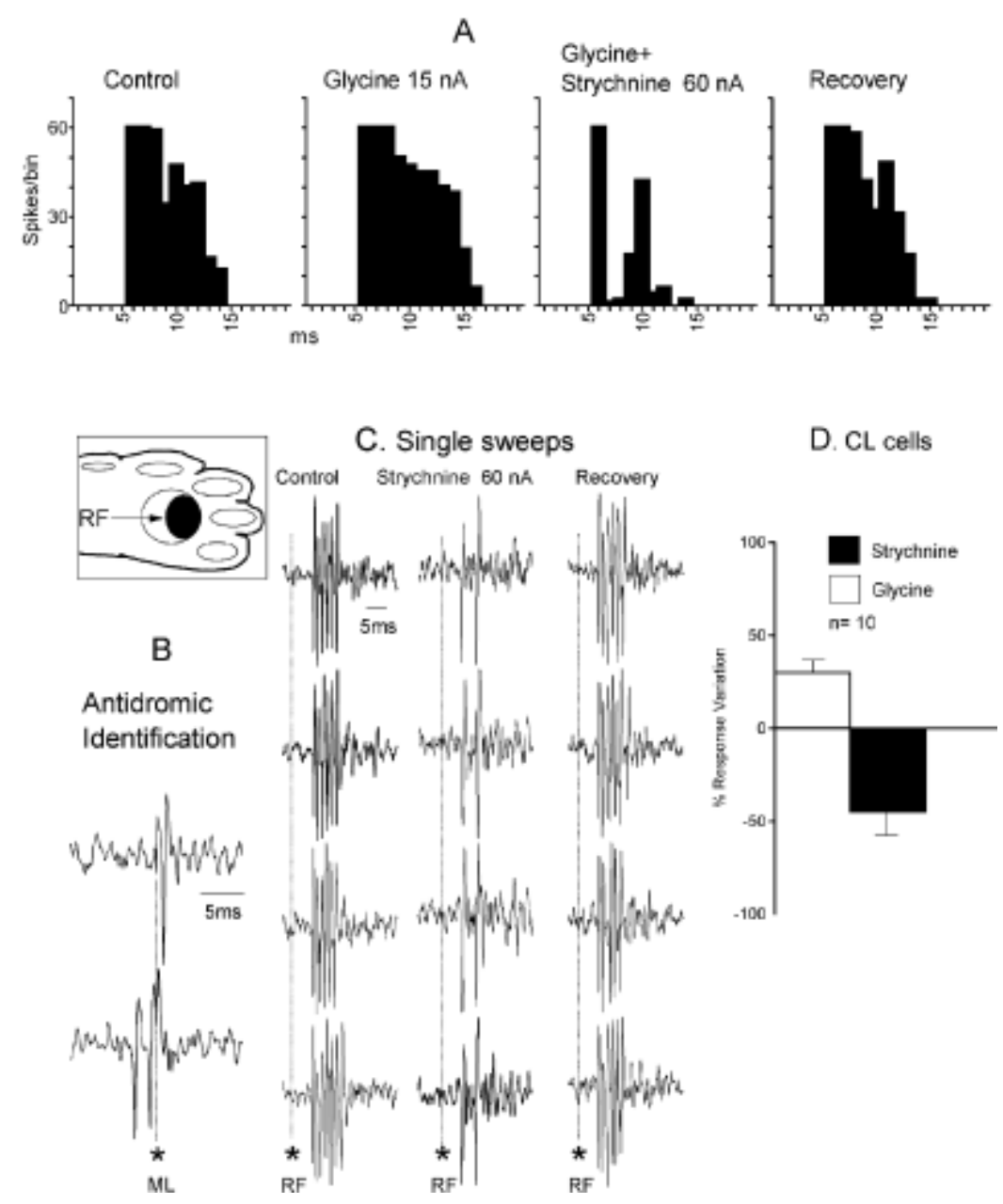

Figure 5. Glycine does not inhibit CL neurons. CL cell (antidromic identification in B) showing that glycine ejection increased the cutaneous-evoked response and that strychnine not only reversed the effect of glycine but also decreased the response relative to control (A). The columns of four single sweeps in C illustrate the decrease in cutaneous-evoked response produced by strychnine ejection. D shows the effects of glycine and strychnine on the tested CL cells. Stimulus artifacts are indicated by asterisks.

\section{Extracellular recording and iontophoresis}

Five-barreled pipettes attached to a mechanical microdrive were used for extracellular recording and iontophoretic ejection of drugs. Standard controls for $\mathrm{pH}$ and current balancing were used. The centre barrel of each five-barreled electrode was filled with $3 \mathrm{~m} \mathrm{NaCl}$ for recording, one barrel was used for current balancing and each of the remaining three barrels was filled with an aqueous solution of one of the following drugs: d-2-amino-5-phosphonovaleric acid (APV; $50 \mathrm{~mm}, \mathrm{pH}$, NMDA receptor antagonist), 6-cyano-7-nitroquinoxaline-2,3-dione (CNQX; $1 \mathrm{~mm}, \mathrm{pH}$, non-NMDA receptor antagonist), 1-(4-aminophenyl)-4-methyl-7,8-methylenedioxy-5H-2,3-benzodiazepine (GYKI-52466, $2 \mathrm{~mm}, \mathrm{pH} 4.5$, AMPA receptor antagonist), bicuculline methiodide $\left(20 \mathrm{~mm}, \mathrm{pH} 4, \mathrm{GABA}_{\mathrm{A}}\right.$ receptor antagonist), GABA (1 m, pH 4), strychnine $(10 \mathrm{~mm}, \mathrm{pH} 5.5$, glycine receptor antagonist) or glycine (1 m, $\mathrm{pH}$ 3.5). Ejecting DC currents (negative for APV and CNQX, positive for the other drugs) were in the range 10-60 nA for APV and CNQX, 5-20 nA for glycine, 20-40 nA for bicuculline, 10-30 nA for GABA, 20-60 nA for strychnine and 20-70 nA for GYKI-52466. The currents used for APV, GABA, CNQX, glycine and GYKI were established by observing their effects on the activation of single neurons elicited by stimulating their excitatory cutaneous receptive fields; those for bicuculline and strychnine were selected by measuring the current level necessary to reverse the effect of iontophoresed GABA and glycine, respectively. When not in use, each drug barrel was subjected to a retaining 25-nA DC current of opposite polarity to prevent unwanted diffusion from the pipette.

After a cell was clearly isolated from the background, the ML was stimulated (rectangular pulses of $0.05 \mathrm{~ms}$ duration and to a maximum of $1 \mathrm{~mA}$ intensity), and the cells responding antidromically were 
classified as CL neurons. The cutaneous excitatory receptive field was determined by brushing and light touching of the skin, and by a bipolar needle stimulating electrode (9-10-mm intertip separation) thrust into the region of the skin activating the cuneate cell under study with minimal threshold and latency. Rectangular pulses of $0.05-0.5 \mathrm{~ms}$ duration and up to a maximum of $2 \mathrm{~mA}$ intensity were applied to the skin. The effect of peripheral stimulation was averaged for 25-100 trials in control conditions, again during ejection of selected drugs, and finally after recovery. Stability was ascertained by comparing responses collected during the first and the last set of trials, and only cells that showed recovery of responses above $80 \%$ of control values were included in the study. Poststimulus histograms (0.5-1-ms bin) were constructed from the accumulated number of spikes for the total number of sweeps.

\section{Intracellular recording}

In six animals, sharp micropipettes filled with $2.5 \mathrm{~m} \mathrm{~K}^{+}$-acetate $(25-50 \mathrm{M} \Omega$ resistance measured in the neural tissue) were used to record intracellularly from CL and nCL cells activated from the skin while varying the membrane potential by current injection through the recording pipette. The resistance of the micropipette was routinely checked by observing the change in voltage produced by current pulses using an intracellular amplifier in the bridge mode. The bridge was balanced and the capacitance neutralization adjusted to give the fastest step response to a current pulse. In these experiments, no ejection of drugs was made and an additional stimulating electrode was placed over the dorsal column at $\mathrm{C} 2-\mathrm{C} 3$.

Recordings were stored on magnetic tape, and off-line analysis of each session was performed to assess the integrity of the cell during the recording period. The recording electrode was considered to be within the $\mathrm{CN}$ when cellular responses were obtained after gentle tapping and brushing of the ipsilateral forearm. Postmortem histology confirmed that all recordings were obtained from the middle cuneate nucleus (see Fig. 1C).

\section{Results}

Cuneate cells activated by skin stimulation were selected for further study. The sample consists of 96 extracellularly and 22 intracellularly recorded cuneate cells excited by displacing hairs $(n=77,47 \mathrm{CL})$ or by touching the skin $(n=41,21 \mathrm{CL})$ in the distal region of the ipsilateral forearm. The hair-sensitive cells tended to respond to manual stimulation of their excitatory receptive fields, generating brief highfrequency discharges, and they showed rapid adaptation. By contrast, the light touch-sensitive neurons tended to be slow-adapting and responded to taps and to long-lasting indentation of the skin, producing spikes mostly grouped in doublets or triplets separated by variable delays during the stimulating period.

The primary afferent cuneate response is reflexively potentiated through corticocuneate cells topographically aligned. This potentiation starts at an average delay of $17 \mathrm{~ms}$ following the beginning of the cuneate response (Canedo \& Aguilar, 2000). Accordingly, analysis focused on the fast primary response, which showed similar properties to the previously described cortical-induced response (Aguilar et al., 2003).

\section{The cutaneous primary afferent input excites $C L$ and $n C L$ cells through non-NMDA and NMDA receptors}

The excitatory response evoked by cutaneous stimulation on CL and nCL cells was reduced by iontophoretic ejection of APV and/or CNQX. Ejection of APV alone gradually decreased the skininduced activation of the $26 \mathrm{CL}$ and $14 \mathrm{nCL}$ cells tested by an average of $45.4 \pm 15.2 \%$ (Fig. 1A) and $60 \pm 7.6 \%$ of control, respectively. Ejection of CNQX alone decreased the cutaneous-evoked response of these same cells by $65.4 \pm 4.5 \%$ (CL cells, Fig. 1A) and by $70 \pm 3 \%$ (nCL cells) of the control responses. The cutaneous-induced activation of both CL and nCL cells was completely abolished 8-12 min after simultaneous ejection of CNQX and APV. These data are diagrammatically summarized in Fig. 1B.

In the control condition, $\mathrm{CL}$ and $\mathrm{nCL}$ neurons generated trains of action potentials when the current intensity applied to the skin was $\leq 400 \mu \mathrm{A}$ (Fig. 1A). The number of spikes per train was invariably reduced by high-intensity peripheral stimulation and by APV or CNQX ejection. The skin-induced response was differentially blocked by CNQX and APV ejection (see examples in Fig. 1A). Both nonNMDA and NMDA receptors contributed to the response evoked by cutaneous stimulation. The nonNMDA component was more evident at the initial phase of the response, mainly consisting of shortlatency doublets, whereas the NMDA-mediated response constituted the main part of a later phase.

It is now well established that depolarization removes the $\mathrm{Mg}^{2+}$ block of NMDA receptors and allows channel opening in the presence of glutamate. To test the contribution of NMDA receptors to the cutaneous-induced response further, $\mathrm{CL}$ and $\mathrm{nCL}$ neurons were intracellularly recorded and polarized to 
different membrane potentials by DC current injection through the recording electrode while stimulating their excitatory receptive fields. All the CL cells tested $(n=10)$ showed a double excitatory response, the early component decreasing and the late component increasing in amplitude with membrane depolarization (Fig. 2A). By contrast, only three of $12 \mathrm{nCL}$ cells tested showed a similar response (Fig. 2, B1) whereas the remaining nine nCL neurons did not vary the structure of the response with membrane depolarization (Fig. 2, B3, $n=6$ ) or increased the number of spikes without changing the duration of the postsynaptic depolarization induced by cutaneous stimulation (Fig. 2, B2, n=3). Note that other different nCL cells showing a similar behaviour to the cell illustrated in Fig. 2, B3 were not included in the study because upon hyperpolarization they generated strong oscillations and deteriorated. Accordingly, the six nCL cells analysed were not hyperpolarized. Furthermore, another key feature of the nCL cells, exemplified by the neuron shown in Fig. 2, B3, was that they generated bursting responses of 5-7 spikes at rest and had resting membrane potentials of between -40 and $-48 \mathrm{mV}$; it is thus probable that the NMDA receptors, if present, were already fully activated at rest.

A. CL cells
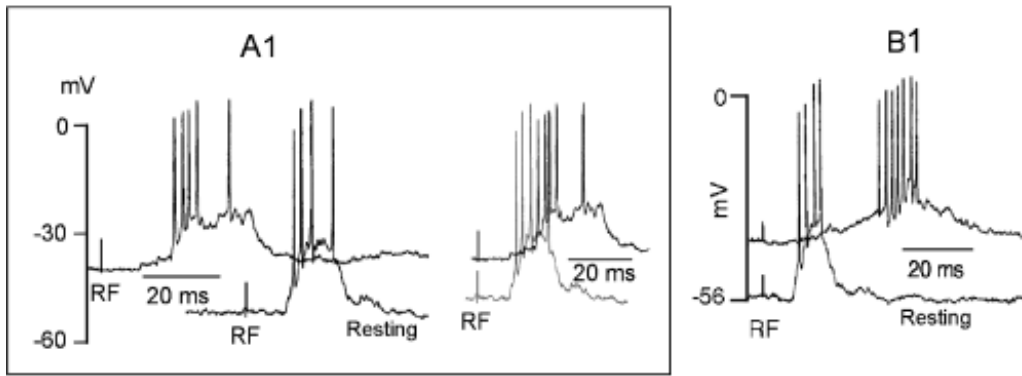

$\mathrm{mV}$

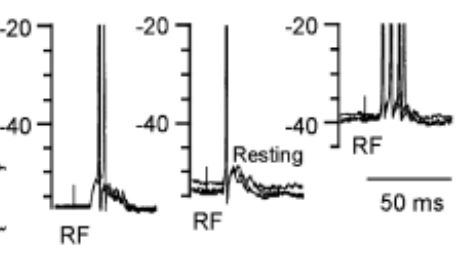

B3
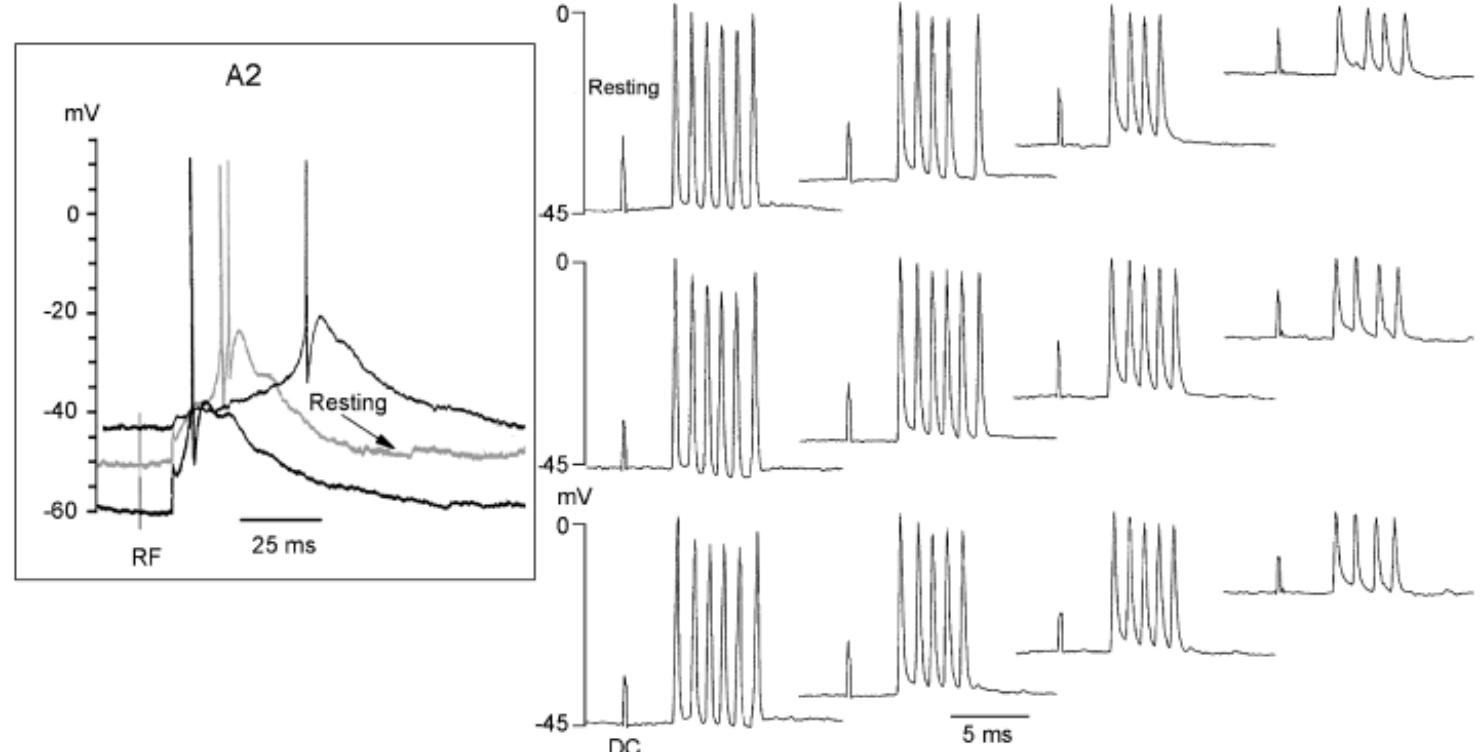

Figure 2 Effect of membrane polarization on the primary afferent-evoked response. (A) Two different CL cells (A1, hair-sensitive; A2, light touch-sensitive) whose cutaneous-evoked responses showed two components (RF indicates the stimulus artifacts), the first decreasing and the second increasing with membrane depolarization, which suggests that the second component may be NMDAdependent. (B) Three different nCL neurons (B1 and B3, hair-sensitive; B2, light touch-sensitive). Upon depolarization, the nCL cell in $\mathrm{B} 1$ shows a

\section{Blocking of AMPA receptors delayed and reduced the cutaneous response}

Because concurrent ejection of a non-NMDA antagonist, unable to distinguish between AMPA and kainate receptors (CNQX), and APV totally blocked the cutaneous response (Fig. 1A), we reasoned that if simultaneous ejection of a specific AMPA blocker (GYKI-52466) and APV do not annul the cutaneous response, the remnant activity would probably be kainate-mediated. Iontophoretic ejection of GYKI- 
52466 and APV was tested on the cutaneous-induced response in a total of 20 cuneate cells (12 CL, Fig. 3). Ejection of GYKI alone decreased the cutaneous response of all CL and nCL cells tested by $44.5 \pm 11.2 \%$ and by $46.4 \pm 10.8 \%$ of the control responses, respectively. GYKI ejection delayed the cutaneous response by selectively blocking the fastest spikes (Fig. 3). Concurrent ejection of GYKI and APV reduced the cutaneous response of these same cells by $80.1 \pm 5.2 \%$ (CL cells, Fig. 3A) and by $81 \pm 4.8 \%$ (nCL cells, Fig. 3B), respectively. These data are diagrammatically quantified in the inset to Fig. 3, A3. A normal cutaneous-induced activity close to $20 \%$ of control remained after simultaneous ejection of GYKI and APV. Together, these results strongly suggest that the later spikes of the primary afferent response were probably NMDA- and kainate-mediated.

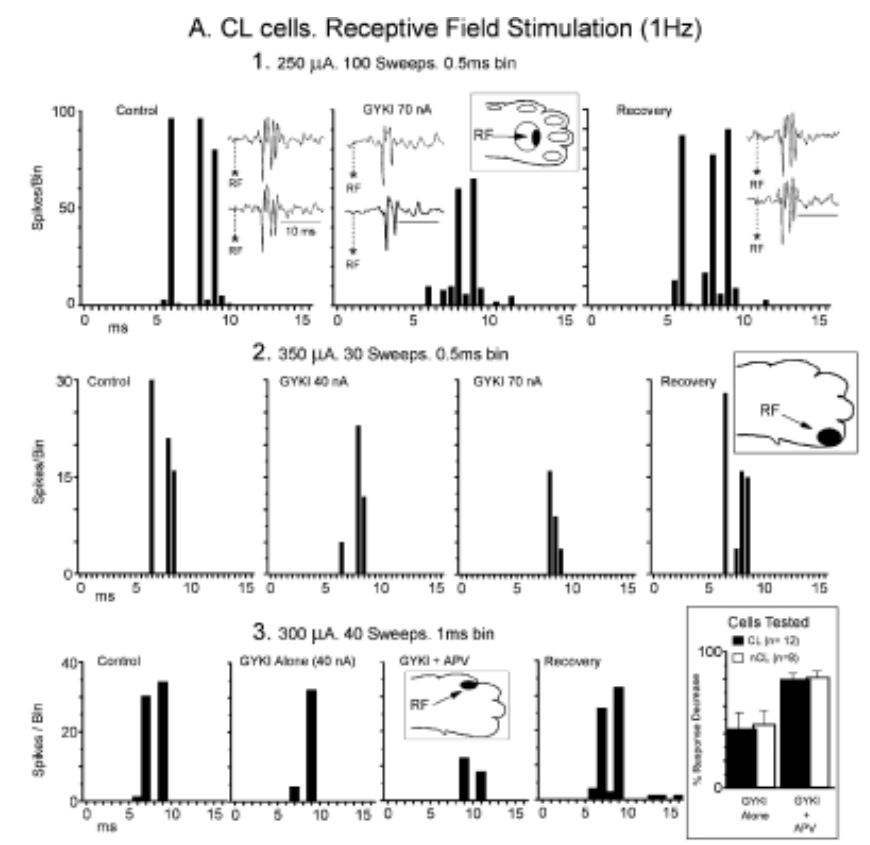

B. $\mathrm{nCL}$ cells. Receptive Field Stimulation $(1 \mathrm{~Hz})$

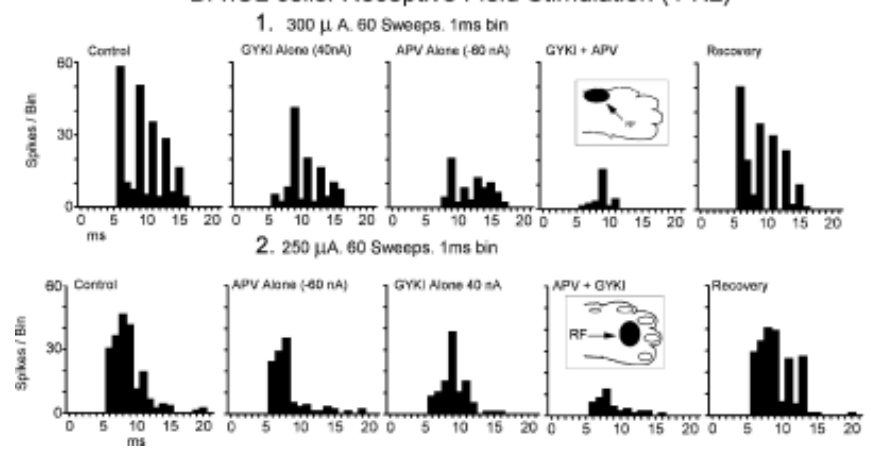

Figure 3 Blockade of AMPA receptors decreases and delays the excitatory cutaneous response of CL and nCL cells. Iontophoretic ejection of GYKI decreased the cutaneous-induced response of three different CL neurons (A1, A2 and A3) and two distinct nCL cells (B1, B2). Subsequent concurrent ejection of GYKI and APV did not totally suppress the cutaneous-induced response. Note that whereas APV alone (B1 and B2) tended to decrease the late phase of the response, GYKI alone tended to decrease the fastest spikes (A and $\mathrm{B})$. The inset in A3

\section{Bicuculline increases and strychnine decreases the cutaneous-evoked activity of CL neurons}

Ten CL neurons were tested with GABA and bicuculline. GABA affected these cells, decreasing the primary afferent response by $70 \pm 11.2 \%$ of the control response. Subsequent ejection of bicuculline not only reversed the effect of GABA but also increased the primary response by $80.5 \pm 19.5 \%$ relative to control, thus demonstrating the specificity of the GABA effect (Fig. 4, A1 and B1). Furthermore, bicuculline uncovered the bursting discharges masked by high-intensity (1-2 mA) receptive field (RF) 
stimulation (Fig. 4, A1, B1 and B3). These data indicate that the GABAergic inhibitory interneurons monosynaptically influence CL cells.

The cutaneous-induced activation of ten CL cells was examined after the ejection of glycine and its antagonist, strychnine. Contrary to what it would be expected for an inhibitory neurotransmitter, glycine ejection increased the cutaneous-evoked response of the CL cells above control levels by $30.6 \pm 6.5 \%$ (Fig. 5A and D). Subsequent ejection of strychnine fully reversed the excitatory effect of glycine and further produced an additional decrease of the cutaneous-evoked response by $45.2 \pm 12.4 \%$ of control (Fig. 5A, C and D), thus demonstrating the specificity of the glycine effect. These results indicate that the glycinergic inhibitory interneurons di- or polysynaptically influence CL cells.

\section{Two distinct classes of $n C L$ cells}

The cutaneous-induced response of $16 \mathrm{nCL}$ neurons tested and recorded at depths where the CL neurons were encountered showed two characteristically distinct responses after glycine and strychnine ejection. The primary response in one class of these nCL cells $(n=9)$ decreased the cutaneous-evoked response by $75 \pm 16 \%$ of control after glycine (Fig. 6A). Simultaneous ejection of strychnine reversed the effect of glycine and further increased the cutaneous-induced response by $62.4 \pm 18 \%$ of control. In addition, strychnine unmasked the bursting discharges suppressed by high-intensity cutaneous stimulation in this subgroup of nCL cells (Fig. 6A). We have labelled this subclass as nCL1 neurons.

$\mathrm{nCL}$ neurons. RF Stimulation; $1 \mathrm{~Hz}, 1 \mathrm{~ms}$ bin
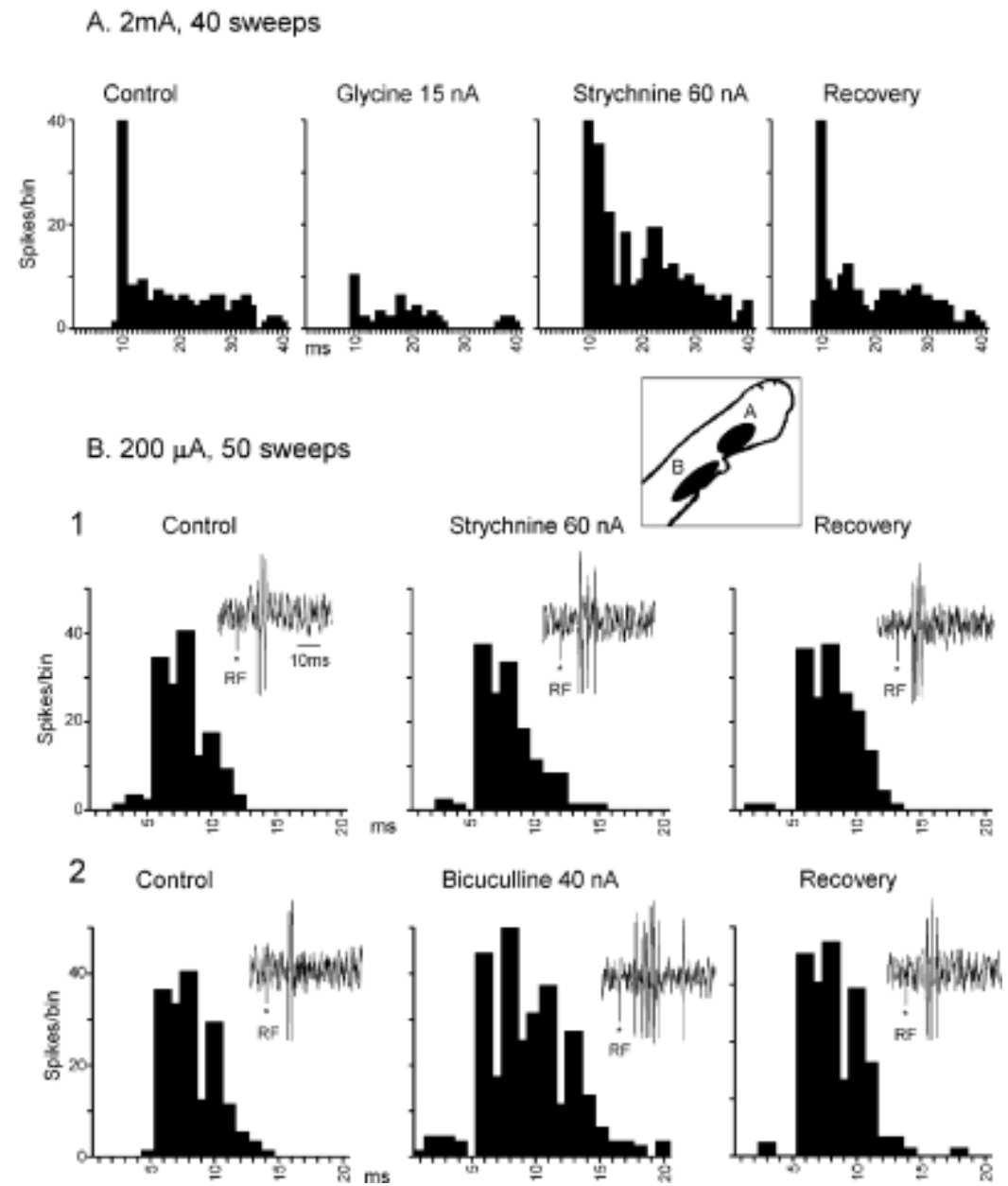

Figure 6 Two different classes of nCL neurons. The nCL neurons could be classified according to their sensitivity (A, nCL1 neuron) or insensitivity (B, nCL2 neuron) to strychnine. Both classes of nCL cells were bicuculline-sensitive (B2). The approximate receptive fields of the $\mathrm{nCL}$ cells illustrated in $\mathrm{A}$ and $\mathrm{B}$ are shown in the inset. The insets in $\mathrm{B}$ show single responses to RF stimulation for each treatment, with the electrical stimuli applied to the skin indicated by asterisks. 
The remaining seven nCL neurons were not affected by glycine or by strychnine (Fig. 6, B1) even after increasing the intensity (up to $150 \mathrm{nA}$ ) and/or the duration (up to $20 \mathrm{~min}$ ) of the ejecting current. We have labelled this subclass as nCL2 neurons. Both nCL1 and nCL2 cells were bicuculline-sensitive, increasing their cutaneous-evoked responses by $54 \pm 12.3 \%$ of control after ejection of the $\mathrm{GABA}_{\mathrm{A}}$ antagonist (Fig. 6, B2).

In summary, similar to previous data related to the somatosensory cortical-evoked response (Aguilar et al., 2003), two subpopulations of nCL neurons could be distinguished in the $\mathrm{CN}$ based on their sensitivity (nCL1) or insensitivity (nCL2) to glycine and strychnine when tested on the primary afferent cutaneous-evoked response.

\section{Discussion}

This study describes the cellular mechanisms through which sensory information from the skin is relayed to cuneate CL and $\mathrm{nCL}$ cells, as well as the intracuneate circuitry used to elaborate the output signal. There is extensive information regarding the anatomical and physiological properties of the $\mathrm{CN}$, including the circuitry utilized by cortical afferents to shape the cortico-cuneate responses (Aguilar et al., 2003); however, a fundamental question regarding the mechanism of transmission from the primary afferents to the nucleus remained unanswered.

Our three main findings are as follows. (i) The primary afferents exert a bimodal monosynaptic effect on CL and nCL neurons through non-NMDA and NMDA receptors. The non-NMDA component of the response is the fastest and due largely, if not solely, to AMPA receptors, whereas a late component is mediated through kainate and NMDA receptors. (ii) The primary afferent-induced activation of CL cells is enhanced by glycine and bicuculline and decreased by strychnine and GABA. (iii) Two classes of interneurons are distinguished based on their sensitivity to glycine and strychnine.

The nCL cells tested may serve to modulate the ascending transmission of cutaneous information because they were recorded at the same depths as the CL cells $(0.6-1.7 \mathrm{~mm})$ and had cutaneous receptive fields. This contrasts with reportedly nCL neurons located more ventrally and receiving proprioceptive information (Berkley et al., 1986; Rustioni \& Weinberg, 1989), which may be more implicated in the modulation of movement-related or posture-related signals.

Synaptic transmission can be affected pre- and postsynaptically. The present discussion deals with postsynaptic mechanisms because experiments addressed specifically to study the presynaptic modulation of the primary response are currently in progress.

\section{Primary afferent activation of CL and $n C L$ neurons}

\section{CL cells}

The primary afferents entering the $\mathrm{CN}$ originate from dorsal root ganglia neurons and release the neurotransmitter glutamate (Salt \& Hill, 1983; Rustioni \& Weinberg, 1989; De Biasi et al., 1994; Deuchars et al., 2000; Núñez \& Buño, 2001). NMDA receptors are present at the CN (Watanabe et al., 1994), and CL and nCL cells also possess AMPA receptors (Popratiloff et al., 1997) although their cellular distribution is unknown. Recent evidence indicates that kainate receptors are also present in the $\mathrm{CN}$ of monkeys (Carroll et al., 1998) and that they are located in the terminals of primary afferents directed to the gracile nucleus in the rat (Hwang et al., 2001), suggesting a role in the regulation of primary afferent sensory transmission (Kerchner et al., 2001; Lerma et al., 2001; Lerma, 2003). Whether kainate receptors are also postsynaptically located on CL and/or nCL cells is still unknown.

The finding that GYKI blocked the fastest spikes of the cutaneous response together with the fact that concurrent CNQX and APV ejection totally blocked the primary response whereas simultaneous GYKI and APV ejection did not indicates that this later residual activity might have been produced through kainate receptors. Thus the primary cutaneous response is cooperatively produced via three different mechanisms, a fast response mainly via AMPA receptors and slower responses through both NMDA and kainate receptors. Whether kainate receptors may also play a regulatory role in the release of inhibitory neurotransmitters in the $\mathrm{CN}$, as occurs in other systems (Lerma et al., 2001; Binns et al., 2003), remains to be determined.

$n C L$ cells

Although in extracellular records all nCL neurons tested were sensitive to APV, a second intracellularly recorded component in the primary response increasing with membrane potential depolarization could not be demonstrated in nCL cells with low membrane potentials at rest $(-40$ to 
$-48 \mathrm{mV}, n=6$ ) nor in three other nCL neurons with more negative resting potentials. In the former case, it is likely that the NMDA receptors were already fully activated at rest. In the latter case, the number of spikes per trial increased with membrane depolarization without changes in the duration of the excitatory postsynaptic potentials, which also points towards the participation of NMDA receptors.

\section{Relation to previous work and functional significance}

Previous studies combining iontophoresis and cellular recording have shown that 1-hydroxy-3aminopyrrolid-2-one (HA-966) depresses synaptically and chemically activated cells in the CN of the cat (Davies \& Watkins, 1973a, b). HA-966 is now known to be a functional antagonist at the strychnineinsensitive glycine site of the NMDA receptor complex. Recent work conducted in vitro either confirmed (Deuchars et al., 2000) or refuted (Núñez \& Buño, 2001) the contribution of NMDA receptors to the response of DCN neurons when stimulating the primary afferents. The present results demonstrate that NMDA receptors do intervene in the primary afferent synaptic transmission through $\mathrm{CN}$ in the cat.

The NMDA component of the primary response depends on the concentration of the coagonist glycine in the synaptic cleft, whose active release is probably produced by glycinergic nCL neurons that also disinhibit cuneolemniscal transmission (see below). Under physiological conditions, the activation of AMPA receptors initiates transient depolarization and excitation, leading to the fast component of the primary cutaneous response, whilst the activation of both NMDA and kainate receptors underlies a slower component. Presynaptic release of glutamate and consequent depolarization of the postsynaptic neuronal membrane via AMPA receptor-coupled channels relieves the $\mathrm{Mg}^{2+}$ blockade of the ion channel associated with the NMDA receptor at resting conditions. This allows $\mathrm{Ca}^{2+}$ influx to the cell which, in turn, may trigger different forms of synaptic plasticity and, if in excess, may lead to excitotoxicity through depolarization of the mitochondrial membrane and to a subsequent decrease in ATP synthesis, among other mechanisms (Choi, 1992; Garthwaite, 1994; Lipton \& Rosenberg, 1994). The excessive activation of NMDA receptor-coupled channels could be prevented through the regulation of glutamate release by kainate autoreceptors present in the primary afferent terminals (Hwang et al., 2001). Kainate receptors are slower than AMPA receptors, display rapid desensitizing responses (Lerma et al., 2001) and are depressed by low external sodium concentration brought about by intense neuronal activity (Paternain et al., 2003). These features make kainate receptors less sensitive to glutamate released by later action potentials during repetitive firing (Paternain et al., 2003). Accordingly, presynaptic kainate receptors may contribute, together with NMDA postsynaptic receptors, to the late component of the primary afferent response and may also lessen the duration of the response by down-regulating the release of glutamate.

The propensity of cuneate cells to generate high-frequency bursting discharges may also reflect intrinsic properties. It was recently reported that cultured DCN neurons devoid of synaptic influence, from 10- to 15-day-old rats, do generate bursts, with the number of spikes per burst increasing with depolarized membrane potentials (Reboreda et al., 2003; see their figs 2A and 3A). These bursts retained almost invariably the interburst interval, at variance with the changes in interburst intervals observed in in vivo preparations. A role of the internal $\mathrm{CN}$ circuitry may be not only to modulate the level of membrane potential but also to regulate bursting frequency. In the $\mathrm{CN}$, bursting is also regulated by excitatory axon recurrent collaterals of CL neurons topographically aligned re-entering the nucleus (Aguilar et al., 2002).

\section{Primary afferent inhibition and disinhibition of CL cells}

Inhibitory modulation in the rat DCN is provided by intrinsic inhibitory interneurons releasing GABA, glycine or both neurotransmitters (Popratiloff et al., 1996). GABAergic interneurons synapse mainly on the proximal regions of CL cells (Lue et al., 1994), whereas glycinergic interneurons appear to synapse in the distal dendrites in the same species (Popratiloff et al., 1996; Lue et al., 2000). It is unknown whether the above also applies to the cat.

GABA ejection decreased the cutaneous-elicited activity of all CL neurons tested, an effect that was reversed by the $\mathrm{GABA}_{\mathrm{A}}$ antagonist bicuculline. This indicates that the primary afferent-induced inhibition shaping the cuneolemniscal transmission is produced through GABAergic interneurons. These effects of GABA reversed by bicuculline were probably produced through postsynaptic $\mathrm{GABA}_{\mathrm{A}}$ receptors because the $\mathrm{GABA}_{\mathrm{B}}$ receptors appear to be restricted to the presynaptic primary afferent terminals (Deuchars et al., 2000) and are bicuculline-resistant (Hill \& Bowery, 1981). Nonspecific effects of bicuculline increasing neuronal excitability by blocking $\mathrm{Ca}^{2+}$-activated potassium currents have been reported in other systems (Seutin et al., 1997; Debarbieux et al., 1998). However, different lines of evidence already discussed at length (Aguilar et al., 2003) suggest a postsynaptic $\mathrm{GABA}_{\mathrm{A}}$-mediated action of bicuculline in the cuneate nucleus. 
Glycine increased and strychnine decreased the cutaneous-evoked activation of CL neurons, indicating that the glycine receptors of CL cells, if present, were not influenced by iontophoretic ejection of agonist and antagonist. These results indicate that the strychnine-dependent effect of glycine is indirectly produced on CL cells and suggest that the glycinergic interneurons disinhibit CL cells topographically aligned through GABAergic interneurons (Fig. 7). This, together with previous results, points to a common intracuneate circuitry modulating lemniscal-recurrent (Aguilar et al., 2002), corticocuneate (Aguilar et al., 2003) and primary afferent information (this study). The primary afferent and recurrent effects ensure a repetitive response and a centre-surround antagonism at low stimulating frequencies. The reflex corticocuneate influence may be more implicated in the transmission of highfrequency signals by maintaining the depolarization of the activated CL cells and potentiating their inhibitory surround, thus incrementing spatial and temporal resolution at prethalamic level.

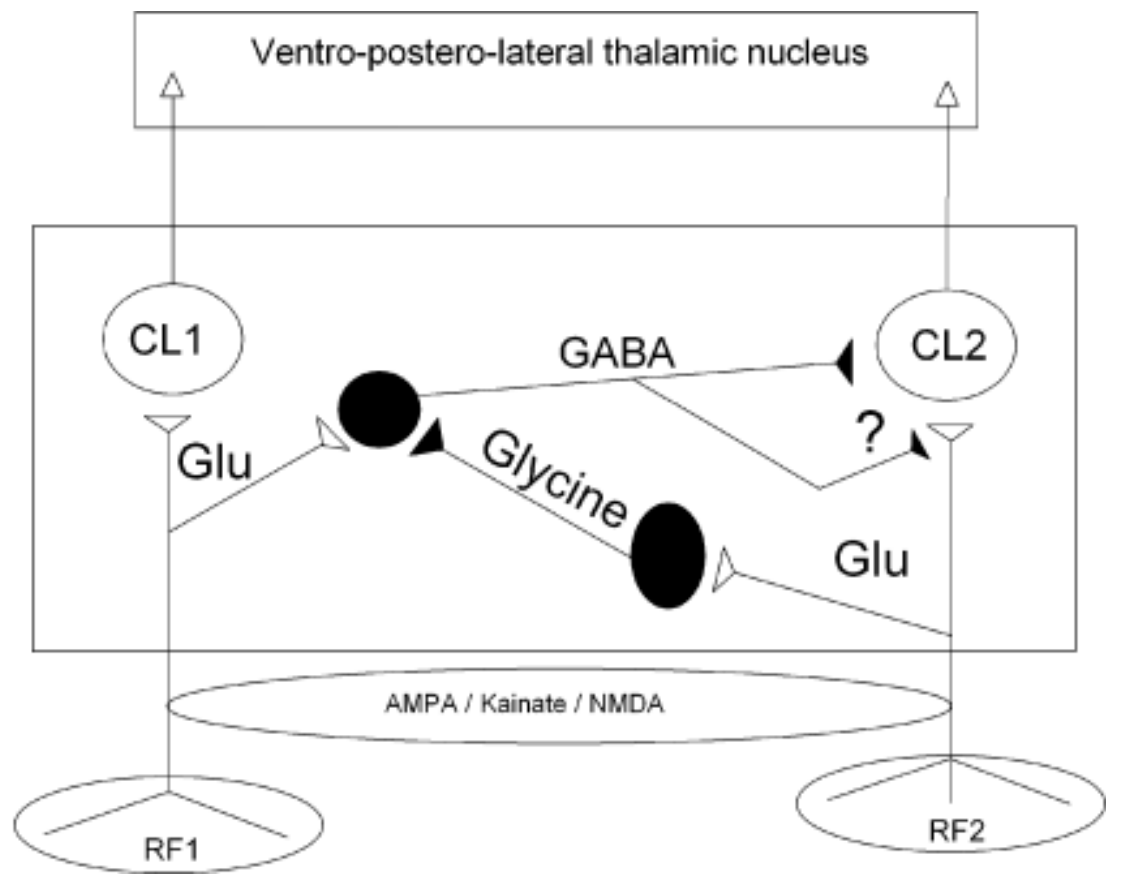

Figure 7. Proposed intracuneate circuitry underlying primary afferent-cutaneous transmission. This shows two populations of CL cells (CL1 and CL2) with different receptive fields (RF1 and RF2). The primary afferent fibers activated by stimulation of a receptive field, for example RF2, excite monosynaptically the CL2 population through AMPA kainate, and NMDA receptors and, at the same time, annul the lateral inhibition induced by population CL1 on population CL2. This disinhibition is brought about through activation of glycinergic interneurons that inhibit the GABAergic interneurons synapsing with the CL2 projection neurons. The cortico-cuneate and cuneolemniscal collateral recurrents influencing the same circuitry have been omitted for clarity.

One of the concerns regarding glycine is its dual role on synaptic transmission. Glycine activates both inhibitory strychnine-sensitive receptors and the NMDA strychnine-insensitive receptor-coupled site. According to the present results, the cuneate glycinergic interneurons may serve two complementary functions at the $\mathrm{CN}$ : to disinhibit CL neurons and to provide glycine to NMDA receptors.

\section{Acknowledgements}

This work was supported by grants from the Ministerio de Ciencia y Tecnología (BFI 2003-01940) and the Xunta de Galicia. The technical assistance of María Pérez is gratefully acknowledged. We express our gratitude to Dr J. A. Lamas for his helpful comments.

\section{Abbreviations}

AMPA amino-3-hydroxy-5-methyl-isoxazol-propionate; APV D-2-amino-5-phosphonovaleric acid; CL cuneo-lemniscal neuron; CN cuneate nucleus; CNQX 6-cyano-7-nitroquinoxaline-2,3-dione; DCN dorsal column nuclei (cuneate and gracilis); GABA gamma aminobutyric acid; GYKI-52466 1-(4- 
aminophenyl)-4-methyl-7,8-methylenedioxy-5H-2,3-benzodiazepine; $\mathrm{ML}$ medial lemniscus; $\mathrm{nCL}$ noncuneolemniscal neuron; NMDA $N$-methyl-d-aspartate.

\section{References}

Aguilar, J., Rivadulla, C., Soto, C. \& Canedo, A. (2003) New corticocuneate cellular mechanisms underlying the modulation of cutaneous ascending transmission in anesthetized cats. J. Neurophysiol., 89, 3328-3339.

Aguilar, J., Soto, C., Rivadulla, C. \& Canedo, A. (2002) The lemniscal-cuneate recurrent excitation is suppressed by strychnine and enhanced by $\mathrm{GABA}_{\mathrm{A}}$ antagonists in the anaesthetized cat. Eur. J. Neurosci., 16, 1697-1704.

Amassian, V.E. \& De Vito, J.L. (1957) La transmission dans le noyeau de Burdach (nucleus cuneatus). Etude analytique par unités isolées d'un relais somatosensoriel primaire. Colloq. Int. Centre Nat. Rech. Sci., 67, 353393.

Andersen, P., Eccles, J.C., Schmidt, R.F. \& Yokota, T. (1964) Identification of relay cells and interneurons in the cuneate nucleus. J. Neurophysiol., 27, 1080-1095.

Banna, N.R. \& Jabbur, S.J. (1989) Neurochemical transmission in the dorsal column nuclei. Somatosens. Mot. Res., 6, 237-251.

Barbaresi, P., Spreafico, R., Frassoni, C. \& Rustioni, A. (1986) GABAergic neurons are present in the dorsal column nuclei but not in the ventroposterior complex of rats. Brain Res., 282, 305-326.

Berkley, K.J., Budell, R.J., Blomqvist, A. \& Bull, M. (1986) Output systems of the dorsal column nuclei in the cat. Brain Res. Rev., 11, 199-225.

Binns, K.E., Turner, J.P. \& Salt, T.E. (2003) Kainate receptor (GluR5)-mediated disinhibition of responses in rat ventrobasal thalamus allows a novel sensory processing mechanism. J. Physiol., 551, 525-537.

Broman, J. (1994) Neurotransmitters in subcortical somatosensory pathways. Anat. Embryol., 189, 181-214.

Canedo, A. \& Aguilar, J. (2000) Spatial and cortical influences exerted on cuneothalamic and thalamocortical neurons of the cat. Eur. J. Neurosci., 12, 2515-2533.

Canedo, A., Martinez, L. \& Mariño, J. (1998) Tonic and bursting activity in the cuneate nucleus of the chloraloseanesthetized cat. Neuroscience, 84, 603-617.

Carroll, F.Y., Finkelstein, D.I., Horne, M.K., Lawrence, A.J., Crawford, D., Paxinos, G. \& Beart, P.M. (1998) Regional distribution of low affinity kainate receptors in brain of Macaca fascicularis determined by autoradiography using [3H] (2S,4R)-4-methylglutamate. Neurosci. Lett., 255, 71-74.

Choi, D.W. (1992) Excitotoxic cell death. J. Neurobiol., 23, 1261-1276.

Davies, J. \& Watkins, J.C. (1973a) Microelectrophoretic studies on the depressant action of HA-966 on chemically and synaptically excited neurones in the cat cerebral cortex and cuneate nucleus. Brain Res., 59, 311-322.

Davies, J. \& Watkins, J.C. (1973b) Antagonism of synaptic and amino acid induced excitation in the cuneate nucleus of the cat by HA-966. Neuropharmacology, 12, 637-640.

De Biasi, S., Vitellaro-Zuccarello, L., Bernardi, P., Valtschanoff, J.G. \& Weinberg, R.J. (1994) Ultrastructural and immunocytochemical characterization of primary afferent terminals in the rat cuneate nucleus. J. Comp. Neurol., $344,2-15$

Debarbieux, F., Brunton, J. \& Charpak, S. (1998) Effect of bicuculline on thalamic activity: a direct blockade of Iahp in reticularis neurons. J. Neurophysiol., 79, 2911-2918.

Deuchars, S.A., Trippenbach, T. \& Spyer, K.M. (2000) Dorsal column nuclei neurons recorded in a brain stem-spinal cord preparation: characteristics and their responses to dorsal root stimulation. J. Neurophysiol., 84, 1361-1368.

Dykes, R.W., Rasmusson, D.D., Sretavan, D. \& Rehman, N.B. (1982) Submodality segregation and receptive-field sequences in cuneate, gracile, and external cuneate nuclei of the cat. J. Neurophysiol., 47, 389-416.

Fyffe, R.E.W., Cheema, S.S. \& Rustioni, A. (1986) Intracellular staining study of the feline cuneate nucleus. I. Terminal patterns of primary afferent fibers. J. Neurophysiol., 56, 1268-1283.

Garthwaite, J. (1994) NMDA receptors, neuronal development, and neurodegeneration. In Collingridge, G.L. \& Watkins, J.C. (Eds), The NMDA Receptor. Oxford University Press, Oxford, pp. 428-456.

Gordon, G. \& Seed, W.A. (1961) An investigation of the nucleus gracilis of the cat by antidromic stimulation. J. Physiol., 155, 589-601.

Hill, D.R. \& Bowery, R.G. (1981) ${ }^{3}$ H-baclofen and ${ }^{3}$ H-GABA bind to bicuculline-insensitive GABA $_{B}$ sites in rat brain. Nature, 290, 149-152.

Hwang, S.J., Rustioni, A. \& Valtschanoff, J.G. (2001) Kainate receptors in primary afferents to the rat gracile nucleus. Neurosci. Lett., 312, 137-140.

Kerchner, G.A., Wilding, T.J., Li, P., Zhoum, M. \& Huettner, J.E. (2001) Presynaptic kainate receptors regulate spinal sensory transmission. J. Neurosci., 21, 59-66.

Kuypers, H.G.J.M. \& Tuerk, J.D. (1964) The distribution of the cortical fibres within the nucleus cuneatus and gracilis in the cat. J. Anat., 98, 143-162.

Lerma, J. (2003) Roles and rules of kainate receptors in synaptic transmission. Nature Rev. Neurosci., 4, 481-495.

Lerma, J., Paternain, A.V., Rodríguez-Moreno, A. \& López-García, J.C. (2001) Molecular physiology of kainate receptors. Physiol. Rev., 81, 971-998.

Lipton, S.A. \& Rosenberg, P.A. (1994) Excitatory amino acids as a final common pathway for neurological disorders. N. Engl. J. Med., 330, 1261-1276.

Lue, J.-H., Shieh, J.Y., Wen, C.-Y. \& Chen, S.-H. (2000) Cuneothalamic relay neurons are postsynaptic to glycineimmunoreactive terminals in the rat cuneate nucleus. Synapse, 37, 222-231. 
Lue, J.H., Shieh, J.Y., Wen, C.Y., Chen, K.N. \& Chan, S.A. (1994) GABAergic boutons establish synaptic contacts with the soma and dendrites of cuneothalamic relay neurons in the rat cuneate nucleus. Exp. Brain Res., 98, 1320.

Núñez, A. \& Buño, W. (2001) Properties and plasticity of synaptic inputs to rat dorsal column nuclei neurons recorded in vitro. J. Physiol., 535, 483-495.

Paternain, A.V., Cohen, A., Stern-Bach, Y. \& Lerma, J. (2003) A role for extracellular $\mathrm{Na}^{+}$in the channel gating of native and recombinant kainate receptors. J. Neurosci., 23, 8641-8648.

Paternain, A.V., Morales, M. \& Lerma, J. (1995) Selective antagonism of AMPA receptor unmasks kainate receptormediated responses in hippocampal neurons. Neuron, 14, 185-189.

Popratiloff, A., Rustioni, A. \& Weinberg, R.J. (1997) Heterogeneity of AMPA receptors in the dorsal column nuclei of the rat. Brain Res., 754, 333-339.

Popratiloff, A., Valtschanoff, J.G., Rustioni, A. \& Weinberg, R.J. (1996) Colocalization of GABA and glycine in the rat dorsal column nuclei. Brain Res., 706, 308-312.

Ramón y Cajal, S. (1909) Histologie Du Système Nerveux de L'homme et Des Vertébrés. Maloine, Paris.

Reboreda, A., Sánchez, E., Romero, M. \& Lamas, J.A. (2003) Intrinsic spontaneous activity and subthreshold oscillations in neurones of the rat dorsal column nuclei in culture. J. Physiol., 551, 191-205.

Rustioni, A. \& Weinberg, R.J. (1989) The somatosensory system. In Björklund, A., Hökfelt, T. \& Swanson, L.W. (Eds), Handbook of Chemical Neuroanatomy: Integrated Systems of the CNS. Elsevier, Amsterdam, pp. 219321.

Salt, T.E. \& Hill, R.G. (1983) Neurotransmitter candidates of somatosensory primary afferent fibres. Neuroscience, $10,1083-1103$.

Schwartzkroin, P.A., Duijn, H.V. \& Prince, D.A. (1974) Effects of projected cortical epileptiform discharges on unit activity in the cat cuneate nucleus. Exp. Neurol., 43, 106-123.

Seutin, V., Scuvee-Moreau, J. \& Dresse, A. (1997) Evidence for a non-GABAergic action of quaternary salts of bicuculline on dopaminergic neurones. Neuropharmacology, 36, 1653-1657.

Watanabe, M., Mishina, M. \& Inoue, Y. (1994) Distinct distributions of the NMDA receptor channel subunit mRNAs in the brainstem. J. Comp. Neurol., 343, 520-531. 